\title{
ANALISIS FAKTOR YANG MEMPENGARUHI PERPINDAHAN MEREK (BRAND SWITCHING) PENGGUNA JARINGAN OPERATOR TRI KE OPERATOR LAIN DI MASA PEMBELAJARAN ONLINE SAAT PANDEMI COVID -19
}

(Studi Kasus Mahasiswa/i Universitas Islam As-Syafi'iyah)

\author{
Chusnah SE.MM \\ Zahratunnisa \\ Chusnahchoyib28@gmail.com
}

\begin{abstract}
This researchs purpose to know some factors that influence brand switching Tri operator user to another operator and get result from the pre-survey include the effect of product atribute, variety seeking, promotion and price on brand switching. This research obtained via by questionnaire to 96 respondents which become Tri operator user to students at the As- syafi'iyah Islamic University with population 3.850. Analyst data method that used is regression analysis, correlation, coefficient of determination and hypothesis test. Based on analyst data result, partially product attributes give positive and significant effect on brand switching. Variety seeking give positive and significant effect on brand switching. Promotion give positive and significant effect on brand switching. Price give positive and significant effect on brand switching.
\end{abstract}

\section{Keyword : Product Attribute, Variety Seeking, Promotion, Price and Brand Switching}

\begin{abstract}
Abstrak
Penelitian ini bertujuan untuk mengetahui faktor-faktor apa saja yang mempengaruhi perpindahan merek pengguna operator Tri ke operator lain dan didapat dari hasil pra survey diantaranya pengaruh atribut produk, variety seeking, promosi dan harga terhadap perpindahan merek. Data penelitian ini diperoleh dengan menyebarkan kuesioner kepada 96 responden yang menjadi pengguna operator Tri pada mahasiswa di Universitas Islam As-Syafi'iyah dengan jumlah populasi 3.850. Metode analisis data yang digunakan adalah analisis regresi, korelasi, koefisien determinasi dan uji hipotesis. Berdasarkan hasil analisis data, secara parsial atribut produk berpengaruh positif dan signifikan terhadap perpindahan merek. Variety seeking berpengaruh positif dan signifikan terhadap perpindahan merek. Promosi berpengaruh positif dan signifikan terhadap perpindahan merek. Harga berpengaruh positif dan signifikan terhadap perpindahan merek.
\end{abstract}

Kata Kunci: Atribut Produk, Variety Seeking, Promosi, Harga dan Perpindahan Merek

\section{PENDAHULUAN}

\section{Latar Belakang}

Jaringan operator telekomunikasi semakin diperlukan bagi masyarakat untuk memenuhi kebutuhannya terkhusus dalam pembelajaran online saat pandemi covid-19. Saat ini di tahun 2021, jaringan telekomunikasi bukan hanya untuk kesenangan semata saja melainkan untuk memenuhi kegiatan dari aktivitas sehari-hari masyarakat diantaranya kegiatan pendidikan, perkantoran hingga aktivitas bisnis yang sedang dijalankan. 
Bulan Maret 2020 Indonesia sedang mengalami musibah virus Covid-19 yang dirasakan di seluruh dunia. Saat itu kegiatan yang dilakukan di luar rumah seperti pendidikan, pekerjaan hingga kegiatan perekonomian dilakukan di dalam rumah, tanpa terkecuali kegiatan pendidikan yang mengharuskan dilakukan secara daring (online). Saat itu juga Kementerian Pendidikan dan Kebudayaan RI membuat aturan serta sistem baru dari pembelajaran online dan untuk keberlangsungan pembelajaran online maka siswa, mahasiswa, guru, dosen hingga staff pendidikan lainnya memerlukan kuota jaringan internet. Hal ini menunjukan perilaku dari pengguna jaringan operator Tri tidak mendapatkan kepuasan dari produk (jasa) yang mereka rasakan yaitu dari layanan internet yang kurang baik bahkan mereka beralih jaringan ke merek lain. Sebab dalam keberlangsungan pembelajaran online di saat pandemi Covid-19 maka pendidik maupun pengajar perlu layanan internet yang baik.

Sudah banyak perusahaan jaringan operator telekomunikasi yang beroperasi di Indonesia, diantaranya telkomsel, tri, xl, indosat, smartfren dan masih banyak lagi. Semua jaringan operator yang ditawarkan pastinya memberikan yang terbaik untuk para konsumennya dan membuat sejumlah jaringan operator seluler mengalami pertumbuhan yang sangat pesat.

Tabel 1.1

Penjualan Kartu Seluler 2017 - 2020

\begin{tabular}{|c|r|r|r|r|r|r|r|r|}
\hline KARTU & \multicolumn{2}{|c|}{$\mathbf{2 0 1 7}$} & \multicolumn{2}{|c|}{$\mathbf{2 0 1 8}$} & \multicolumn{2}{|c|}{$\mathbf{2 0 1 9}$} & \multicolumn{2}{|c|}{$\mathbf{2 0 2 0}$} \\
\hline TELKOMSEL & $41 \%$ & 196.000 .000 & $43 \%$ & 167.800 .000 & $41 \%$ & 176.200 .000 & $46 \%$ & 183.000 .000 \\
\hline INDOSAT & $15 \%$ & 110.000 .000 & $18 \%$ & 64.100 .000 & $22 \%$ & 116.000 .000 & $19 \%$ & 119.000 .000 \\
\hline SMARTFREN & $9 \%$ & 12.000 .000 & $10 \%$ & 6.000 .000 & $14 \%$ & 27.000 .000 & $16 \%$ & 55.000 .000 \\
\hline TRI & $\mathbf{2 0} \%$ & $\mathbf{6 8 . 3 0 0 . 0 0 0}$ & $\mathbf{1 1} \%$ & $\mathbf{4 5 . 0 0 0 . 0 0 0}$ & $\mathbf{7 \%}$ & $\mathbf{4 0 . 0 0 0 . 0 0 0}$ & $\mathbf{5 \%} \%$ & $\mathbf{3 8 . 0 0 0 . 0 0 0}$ \\
\hline XI & $15 \%$ & 53.000 .000 & $18 \%$ & 42.000 .000 & $16 \%$ & 55.500 .000 & $14 \%$ & 57.000 .000 \\
\hline
\end{tabular}

Sumber : databoks.com, apjii.or.id, 2021

Data tersebut menunjukan bahwa kartu seluler Tri mengalami penurunan dalam penjualannya disbanding kartu seluler lainnya. Penyebab terjadinya penurunan penjualan menurut Dharmmesta \& Handoko (2012:10) disebabkan karena faktor internal yang meliputi kualitas produk menurun, service yang diberikan tidak baik, tidak ada ketertarikan dari promosi penjualan dan dari faktor eksternal meliputi perubahan selera konsumen, munculnya produk pesaing yang lebih unggul, kebijakan pemerintah. Dengan diketahuinya penyebab penurunan penjualan tersebut diindikasi bahwa persepsi masyarakat terhadap minat beli suatu produk tersebut menurun yang berakibat konsumen beralih ke merek lain dengan produk sejenis untuk memenuhi kebutuhannya.

Menurut Peter \& Olson (2014:522) perpindahan merek ialah "perubahan sikap konsumen terhadap produk yang dikonsumsinya untuk berganti ke produk lain”. Perpindahan merek salah satu yang menjadi perhatian bagi perusahaan untuk menciptakan produknya sesuai dengan kebutuhan dan keinginan konsumen maka perlu dikaji lebih dalam supaya perusahaan tidak kehilangan konsumennya. Banyak faktor yang dapat mempengaruhi konsumen berpindah merek diantaranya atribut produk, harga, promosi, iklan, coverage, gaya hidup, citra merek, dan variety seeking.

Berdasarkan pra survey pada penelitian ini maka penulis memfokuskan pada persentase tertinggi dari faktor atribut produk, variety seeking (mencari varians baru), promosi dan juga harga. Penulis juga mengambil perusahaan telekomunikasi karena di saat pandemi kegiatan pembelajaran dilakukan secara daring (online) yang mana membutuhkan kuota internet untuk dapat keberlangsungan pembelajaran online tersebut. 
Beberapa hasil penelitian terdahulu yang membahas tentang variabel terkait dalam penelitian ini, yaitu :

Nurma Elita Sari pada tahun 2016 dengan judul "Pengaruh Promosi, Harga, Atribut Produk, Citra Merek dan Variety Seeking Terhadap Keputusan Perpindahan Merek pada Konsumen Jasa Layanan Internet Lain Ke FastNet PT. First Media Tbk", hasil penelitian menunjukan variabel promosi, harga, atribut produk, citra merek dan variety seeking secara simultan dan parsial memiliki pengaruh positif terhadap perilaku brand switching pengguna jasa layanan internet lain ke FastNet PT. First Media Tbk.

Ana Nurjanah pada tahun 2017 dengan judul " Faktor-Faktor Yang Berpengaruh Terhadap Perilaku Brand Switching Pada Kartu Seluler”, hasilnya menunjukan secara simultan pengaruh atribut produk, harga, kepuasan, promosi dan variety seeking berpengaruh positif terhadap perpindahan merek (brand switching) kartu seluler.

Reni Purnama Sari pada tahun 2019 dengan judul "Pengaruh Harga, Atribut Produk, Promosi dan Variety Seeking Terhadap Brand Switching Paket Internet Kartu Perdana Simpati ke Axis", hasilnya menyimpulkan secara parsial dan simultan pengaruh harga, atribut produk, promosi dan variety seeking terhadap brand switching paket internet kartu perdana simpati ke axis berpengaruh positif.

Berdasarkan uraian permasalahan diatas, maka penulis melakukan penelitian dengan judul "Analisis Faktor Yang Mempengaruhi Perpindahan Merek (Brand Switching) Pengguna Jaringan Operator Tri ke Operator Lain di Masa Pembelajaran Online Saat Pandemi Covid-19 (Studi Kasus Mahasiswa/i Universitas Islam As-Syafi'iyah)".

\section{Perumusan Masalah}

Dari uraian latar belakang di atas, maka perumusan masalah penelitian ini :

1. Apakah atribut produk berpengaruh terhadap perpindahan merek pengguna jaringan operator Tri ke operator lain?

2. Apakah variety seeking berpengaruh terhadap perpindahan merek pengguna jaringan operator Tri ke operator lain?

3. Apakah promosi berpengaruh terhadap perpindahan merek pengguna jaringan operator Tri ke operator lain?

4. Apakah harga berpengaruh terhadap perpindahan merek pengguna jaringan operator Tri ke operator lain?

\section{Tujuan Penelitian}

Sesuai perumusan masalah, tujuan dari penelitian ini :

1. Untuk mengetahui pengaruh atribut produk terhadap perpindahan merek pengguna jaringan operator Tri ke operator lain.

2. Untuk mengetahui pengaruh variety seeking terhadap perpindahan merek pengguna jaringan operator Tri ke operator lain.

3. Untuk mengetahui pengaruh promosi terhadap perpindahan merek pengguna jaringan operator Tri ke operator lain.

4. Untuk mengetahui pengaruh harga terhadap perpindahan merek pengguna jaringan operator Tri ke operator lain.

\section{TINJAUAN PUSTAKA}




\section{Manajemen}

Menurut Foster \& Sidharta (2019:7) bahwa manajemen ialah "cara yang efektif dan efisien untuk mencapai tujuan perusahaan melalui perencanaan, pengelolaan, kepemimpinan, dan pengendalian sumber daya perusahaan”. Adapun fungsi dari manajemen menurut Nurdiansyah \& Rahman (2019:22) adalah sebagai berikut :

1. Planning (perencanaan), proses penentuan tindakan perusahaan untuk membuat berbagai rencana agar mencapai tujuan yang telah ditentukan.

2. Organizing (pengorganisasian), suatu kelompok organisasi untuk melaksanakan tujuan yang telah ditentukan dengan tugas yang diberikan kepada individu atau organisasi agar tercipta mekanisme untuk menjalankan rencana.

3. Actuating (pengarahan), suatu fungsi petunjuk untuk menggerakan, memotivasi dan pemberian perintah agar efektifitas dan efisien kerja dapat maksimal dalam menciptakan lingkungan kerja yang sehat, dinamis dan sebagainya.

4. Controlling (pengendalian), suatu fungsi aktivitas menilai kinerja apakah sudah benar melaksanakan pekerjaan berdasarkan standar yang dibuat dan apabila terjadi penyimpangan dapat diperbaiki.

\section{Pemasaran}

Fatihudin \& Firmansyah (2019:2) menyatakan bahwa "pemasaran bukan hanya kegiatan menjual ataupun menawarkan produk saja namun lebih dari itu yaitu kegiatan yang mencakup menyimpan serta mensortir".

Salah satu strategi pemasaran supaya dapat efektif dan efisien yaitu dengan mengoptimalkan elemen dalam bauran pemasaran atau disebut "marketing mix". 9P dalam Marketing mix menurut Fatihudin \& Firmansyah (2019:182) :

1. Product, segala bentuk barang atau jasa yang ditawarkan untuk dikonsumsi dan dirasakan manfaatnya untuk memenuhi kebutuhan konsumen.

2. Price, sejumlah uang yang harus dikeluarkan konsumen untuk mendapatkan produk tersebut.

3. Promotion, kegiatan yang dilakukan penjual untuk memperkenalkan serta meyakinkan konsumen terhadap produk yang dijual.

4. Place, tempat perusahaan melakukan bisnis baik tempat offline maupun online.

5. People, karyawan atau pegawai yang berperan penting dalam berbagai bidang perusahaan dalam membantu kegiatan jual beli.

6. Physical Evidence, tampilan fisik yang terlihat berupa produk, pelayanan, tempat dan lainnya.

7. Planning / Marketing Process, strategi perusahaan untuk mencapai tujuannya serta mengembangkan usahanya.

8. People Opinion, pendapat masyarakat terkait produk (barang/jasa) yang ditawarkan dan perlu diperhatikan supaya dapat membangun inovasi baru.

9. Customer Service, dalam sektor jasa, pelayanan pelanggan diartikan sebagai kualitas yang perlu dipersiapkan

\section{Manajemen Pemasaran}

Shinta (2011:1) mengatakan bahwa "suatu usaha dalam kegiatan manajemen pemasaran dengan melalui perencanaan, pengimplementasian serta pengawasan atau pengendalian kegiatan pemasaran supaya dapat tercapai tujuan perusahaan”. 


\section{Perpindahan Merek}

Schiffman \& Kanuk (2015:23) perpindahan merek ialah "perilaku konsumen yang melakukan pergantian merek dari produk yang biasa dikonsumsi dengan produk merek lain karena tidak mendapatkan apa yang diinginkan dari suatu produk tersebut". Penyebab perpindahan merek diantaranya coverage, harga, atribut produk, iklan, promosi, citra merek, variety seeking, gaya hidup, ketidakpuasan.

\section{Atribut Produk}

Musfar (2020:31) menyatakan bahwa atribut produk ialah "beberapa komponen dari produk berupa kualitas, fitur, garansi, kemasan dan pelayanan yang dapat mempengaruhi reaksi konsumen pada produk tersebut".

\section{Variety Seeking}

Schiffman \& Kanuk (2015:97) menyatakan variety seeking (mencari varian) ialah konsumen yang memiliki sikap emosional tinggi dari apa yang tidak didapatkan dari produk yang dikonsumsi sebelumnya dan mereka berpindah ke produk lain untuk mendapatkan varian yang dibutuhkan.

\section{Promosi}

Suryati (2015:59) bahwa promosi ialah "bentuk strategi penjual untuk meningkatkan serta pertumbuhan dari penjualan produk mereka".

\section{Harga}

Firmansyah (2018:180) menyatakan harga ialah produk yang memiliki patokan nilai yang harus dibayarkan konsumen namun tidak memberatkan konsumen, sehingga dapat memiliki produk tersebut karena harga yang dijual sesuai dengan kemampuan finansial konsumen.

\section{METODE PENELITIAN}

\section{Populasi, Sampel dan Sampling}

Populasi dalam penelitian ini yaitu mahasiswa/i aktif S1 Universitas IslamAsSyafi'iyah dengan jumlah populasi sebanyak 3.850 namun yang menjadi jumlah pengguna operator Tri tidak di ketahui secara pasti. Sampel yang didapat 96 responden dengan menggunakan rumus lemeshow dan teknik sampling yang digunakan non probability yaitu purposive sampling dengan kriteria :

1. Responden merupakan mahasiswa/i S-1 berstatus aktif di UIA.

2. Responden harus pernah atau sedang menjadi pengguna jaringan operator Tri.

\section{Teknik Pengumpulan Data}

Teknik pengumpulan data yang dilakukan dengan cara penyebaran kuesioner kepada 92 mahasiswa/i UIA sesuai kriteria responden.

\section{Metode Analisis Data}

Untuk menganalisis hubungan antara variabel dependen terhadap variabel independen penulis menggunakan program SPSS Statistics 25. Hal pertama yang dilakukan pengujian asumsi klasik melalui uji normalitas, uji multikolinearitas, uji 
heterokedastisitas. Selanjutnya dilakukan beberapa pengujian analisis regresi sederhana, korelasi sederhana, koefisien determinasi. Dan terakhir melakukan pengujian hipotesis melalui uji $\mathrm{T}$.

\section{HASIL PENELITIAN}

\section{UJI ASUMSI KLASIK}

\section{Uji Normalitas}
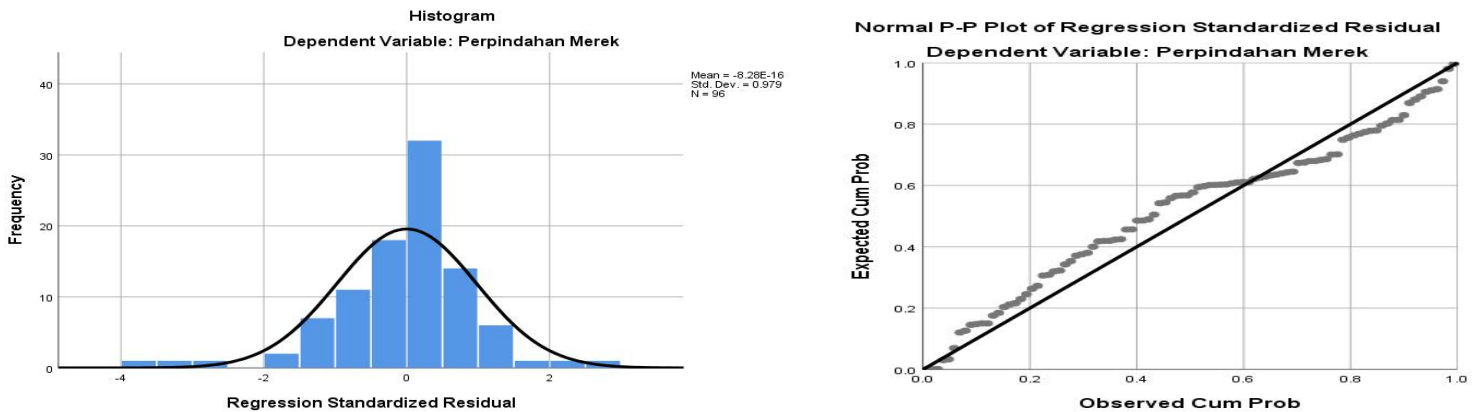

Sumber : Hasil Pengolahan Data SPSS, 2021

Gambar 4.1

Uji Normalitas Histogram dan P-P Plot

Kedua grafik diatas menunjukan bahwa bentuk grafiknya tidak melenceng ke kiri dan kanan serta data menyebar di sekitar garis diagonal dan mengikuti arah garis diagonal, maka dapat dinyatakan data terdistribusi normal.

\section{Uji Multikolinearitas}

Tabel 4.1

Hasil Uji Multikolineritas

\begin{tabular}{|l|r|r|}
\hline \multicolumn{1}{|c|}{ Variabel } & Tolerance & VIF \\
\hline Atribut Produk & $\mathbf{. 6 0 6}$ & $\mathbf{1 . 6 5 1}$ \\
\hline Variety Seeking & $\mathbf{. 5 0 2}$ & $\mathbf{1 . 9 9 0}$ \\
\hline Promosi & $\mathbf{. 5 2 9}$ & $\mathbf{1 . 8 9 0}$ \\
\hline Harga & $\mathbf{. 4 3 9}$ & $\mathbf{2 . 2 7 6}$ \\
\hline
\end{tabular}

Berdasarkan tabel 4.1 menunjukan bahwa semua variabel terbebas dari multikolinearitas karena nilai tolerance $>0,1$ dan nilai $\mathrm{VIF}<10$.

\section{Uji Heterokedastisitas}




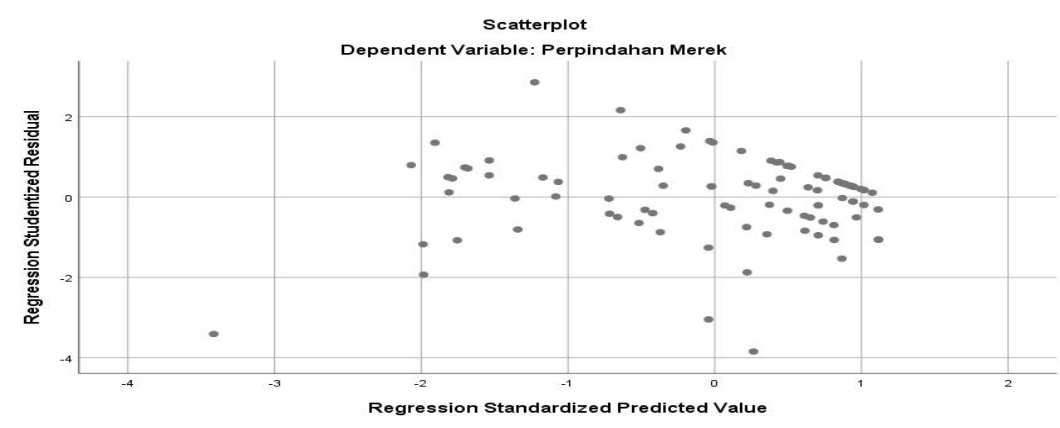

Sumber : Hasil Pengolahan Data SPSS, 2021

Gambar 4.2

Scatterplot

Berdasarkan gambar 4.2 menampilkan hasil bahwa data menyebar merata di sekitar garis diagonal di atas dan di bawah angka 0 (nol) pada sumbu Y maka dapat disimpulkan tidak terjadi heterokedastisitas dalam penelitian ini.

\section{ANALISA REGRESI}

\section{Uji Regresi Sederhana Atribut Produk $\left(X_{1}\right)$ Terhadap Perpindahan Merek (Y)}

Tabel 4.2

Uji Regresi $\mathrm{X}_{1}$ dan $\mathrm{Y}$

\begin{tabular}{|c|c|c|c|}
\hline \multirow{2}{*}{\multicolumn{2}{|c|}{ Model }} & \multicolumn{2}{|c|}{$\begin{array}{l}\text { Unstandardized } \\
\text { Coefficients }\end{array}$} \\
\hline & & B & Std. Error \\
\hline \multirow[t]{2}{*}{1} & (Constant) & 20.910 & 1.459 \\
\hline & Atribut Produk & .526 & .071 \\
\hline
\end{tabular}

Berdasarkan tabel 4.2 bentuk persamaan regresinya $\mathrm{Y}=20,910+0,526 \mathrm{X}_{1}$ dengan penjelasannya yaitu :

$\mathrm{a}=20,910$ sebagai nilai konstanta yang menyatakan apabila tidak ada perubahan dari nilai variabel atribut produk maka nilai dari variabel perpindahan merek adalah 20,910.

$\mathrm{b}=0,526$ sebagai nilai koefisien regresi yang menyatakan apabila nilai dari variabel atribut produk mengalami peningkatan sebesar satu kali maka nilai dari perpindahan merek akan mengalami peningkatan sebesar 0,526 kali.

\section{Uji Regresi Sederhana Variety Seeking $\left(\mathrm{X}_{2}\right)$ Terhadap Perpindahan Merek (Y)}

Tabel 4.3

Uji Regresi $\mathrm{X}_{2}$ dan $\mathrm{Y}$

\begin{tabular}{|l|l|r|r|}
\hline \multirow{2}{*}{\multicolumn{2}{|c|}{}} & \multicolumn{2}{|c|}{$\begin{array}{c}\text { Unstandardized } \\
\text { Coefficients }\end{array}$} \\
\cline { 3 - 4 } Model & \multicolumn{1}{|c|}{ B } & Std. Error \\
\hline \multirow{2}{*}{1} & (Constant) & $\mathbf{1 9 . 8 6 6}$ & 1.477 \\
\cline { 2 - 4 } & Variety Seeking & $\mathbf{. 5 6 0}$ & .070 \\
\hline \multicolumn{2}{|l|}{ a. Dependent Variable: Perpindahan Merek } \\
\hline
\end{tabular}

Berdasarkan tabel 4.3 bentuk persamaan regresinya $\mathrm{Y}=19,866+0,560 \mathrm{X}_{2}$ dengan penjelasannya yaitu : 
$\mathrm{a}=19,866$ sebagai nilai konstanta yang menyatakan apabila tidak ada perubahan dari nilai variabel variety seeking maka nilai dari variabel perpindahan merek adalah 19,866.

$\mathrm{b}=0,560$ sebagai nilai koefisien regresi yang menyatakan apabila nilai dari variabel variety seeking mengalami peningkatan sebesar satu kali maka nilai dari perpindahan merek akan mengalami peningkatan sebesar 0,560 kali.

\section{Uji Regresi Sederhana Promosi $\left(\mathrm{X}_{3}\right)$ Terhadap Perpindahan Merek (Y)}

Tabel 4.4

Uji Regresi $\mathrm{X}_{3}$ dan $\mathrm{Y}$

\begin{tabular}{|c|c|c|c|}
\hline \multirow{2}{*}{\multicolumn{2}{|c|}{ Model }} & \multicolumn{2}{|c|}{$\begin{array}{c}\text { Unstandardized } \\
\text { Coefficients }\end{array}$} \\
\hline & & B & Std. Error \\
\hline \multirow[t]{2}{*}{1} & (Constant) & 20.122 & 1.534 \\
\hline & Promosi & .520 & .069 \\
\hline
\end{tabular}

Berdasarkan tabel 4.4 bentuk persamaan regresinya $\mathrm{Y}=20,122+0,520 \mathrm{X}_{3}$ dengan penjelasannya yaitu :

$\mathrm{a}=20,122$ sebagai nilai konstanta yang menyatakan apabila tidak ada perubahan dari nilai variabel promosi maka nilai dari variabel perpindahan merek adalah 20,122.

$\mathrm{b}=0,520$ sebagai nilai koefisien regresi yang menyatakan apabila nilai dari variabel promosi mengalami peningkatan sebesar satu kali maka nilai dari perpindahan merek akan mengalami peningkatan sebesar 0,520 kali.

\section{Uji Regresi Sederhana Harga $\left(\mathrm{X}_{4}\right)$ Terhadap Perpindahan Merek (Y)}

Tabel 4.5

Uji Regresi $\mathrm{X}_{4}$ dan $\mathrm{Y}$

\begin{tabular}{|c|c|c|c|}
\hline \multirow{2}{*}{\multicolumn{2}{|c|}{ Model }} & \multicolumn{2}{|c|}{$\begin{array}{c}\text { Unstandardized } \\
\text { Coefficients }\end{array}$} \\
\hline & & B & Std. Error \\
\hline \multirow[t]{2}{*}{1} & (Constant) & 19.327 & 1.531 \\
\hline & Harga & .600 & .075 \\
\hline
\end{tabular}

Berdasarkan tabel 4.4 bentuk persamaan regresinya $\mathrm{Y}=19,327+0,600 \mathrm{X}_{4}$ dengan penjelasannya yaitu :

$\mathrm{a}=19,327$ sebagai nilai konstanta yang menyatakan apabila tidak ada perubahan dari nilai variabel harga maka nilai dari variabel perpindahan merek adalah 19,327.

$\mathrm{b}=0,600$ sebagai nilai koefisien regresi yang menyatakan apabila nilai dari variabel harga mengalami peningkatan sebesar satu kali maka nilai dari perpindahan merek akan mengalami peningkatan sebesar 0,600 kali.

\section{ANALISA KORELASI}

1. Uji Korelasi Sederhana Atribut Produk $\left(X_{1}\right)$ Terhadap Perpindahan Merek $(Y)$

Tabel 4.6

Uji Korelasi $\mathrm{X}_{1}$ dan $\mathrm{Y}$

\begin{tabular}{|c|c|c|}
\hline Model & R & R Square \\
\hline 1 & $\mathbf{. 6 0 4}^{\mathbf{a}}$ & .365 \\
\hline
\end{tabular}


a. Predictors: (Constant), Atribut Produk

b. Dependent Variable: Perpindahan Merek

Berdasarkan tabel 4.6 nilai korelasi (r) yang didapat sebesar 0,604 yang artinya hubungan antara variabel atribut produk dan perpindahan merek memiliki hubungan yang kuat dan positif.

\section{Uji Korelasi Sederhana Variety Seeking $\left(\mathrm{X}_{2}\right)$ Terhadap Perpindahan Merek (Y)}

Tabel 4.7

Uji Korelasi $\mathrm{X}_{2}$ dan $\mathrm{Y}$

\begin{tabular}{|c|c|c|}
\hline Model & $\mathbf{R}$ & R Square \\
\hline 1 & $\mathbf{. 6 3 5}^{\mathbf{a}}$ & .404 \\
\hline a. Predictors: (Constant), Atribut Produk \\
b. Dependent Variable: Perpindahan Merek \\
\hline
\end{tabular}

Berdasarkan tabel 4.7 nilai korelasi (r) yang didapat sebesar 0,635 yang artinya hubungan antara variabel variety seeking dan perpindahan merek memiliki hubungan yang kuat dan positif.

\section{Uji Korelasi Sederhana Promosi $\left(\mathbf{X}_{3}\right)$ Terhadap Perpindahan Merek $(\mathbf{Y})$}

Tabel 4.8

\begin{tabular}{|c|c|c|}
\multicolumn{4}{|c|}{ Uji Korelasi $X_{3}$ dan Y } \\
\hline Model & R & R Square \\
\hline 1 & $\mathbf{. 6 1 2}^{\mathbf{a}}$ & .374 \\
\hline a. Predictors: (Constant), Atribut Produk \\
b. Dependent Variable: Perpindahan Merek \\
\hline
\end{tabular}

Berdasarkan tabel 4.8 nilai korelasi (r) yang didapat sebesar 0,612 yang artinya hubungan antara variabel promosi dan perpindahan merek memiliki hubungan yang kuat dan positif.

\section{Uji Korelasi Sederhana Harga $\left(\mathrm{X}_{4}\right)$ Terhadap Perpindahan Merek (Y)}

Tabel 4.9

Uji Korelasi $\mathrm{X}_{4}$ dan Y

\begin{tabular}{|l|c|c|}
\hline Model & R & R Square \\
\hline 1 & $\mathbf{. 6 3 8}^{\mathbf{a}}$ & .407 \\
\hline a. Predictors: (Constant), Atribut Produk \\
b. Dependent Variable: Perpindahan Merek \\
\hline
\end{tabular}

Berdasarkan tabel 4.9 nilai korelasi (r) yang didapat sebesar 0,638 yang artinya hubungan antara variabel harga dan perpindahan merek memiliki hubungan yang kuat dan positif

\section{ANALISA KOEFISIEN DETERMINASI}

Tabel 4.10

Uji Koefisien Determinasi

\begin{tabular}{|c|c|c|}
\hline Model & R & R Square \\
\hline 1 & $.753^{\mathrm{a}}$ & $\mathbf{. 5 6 7}$ \\
\hline
\end{tabular}




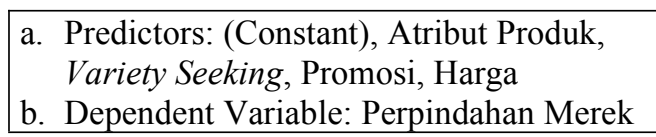

Berdasarkan tabel 4.10 didapat nilai $\mathrm{R}$ Square $\left(\mathrm{R}^{2}\right)$ sebesar 0,567 atau sebesar $56,7 \%$. Hal tersebut berarti variabel dari atribut produk, variety seeking, promosi dan harga mempengaruhi perpindahan merek sebesar $56,7 \%$ dan sisanya $43,3 \%$ dipengaruhi oleh faktor lain diantaranya gaya hidup, citra merek, iklan dan ketidakpuasan.

\section{UJI HIPOTESIS (Uji T)}

\section{Uji T Atribut Produk $\left(\mathrm{X}_{1}\right)$ Terhadap Perpindahan Merek (Y)}

Tabel 4.11

Uji T $\mathrm{X}_{1}$ dan Y

\begin{tabular}{|l|l|r|c|}
\hline \multirow{2}{*}{ Model } & \multicolumn{1}{|c|}{ t } & Sig. \\
\hline \multirow{2}{*}{1} & (Constant) & 14.330 & .000 \\
\cline { 2 - 4 } & Atribut Produk & $\mathbf{7 . 3 5 7}$ & $\mathbf{. 0 0 0}$ \\
\hline \multicolumn{3}{|l}{ a. Dependent Variable: Perpindahan Merek } \\
\hline
\end{tabular}

Berdasarkan tabel 4.11 didapat nilai sig. sebesar 0,000, nilai $t_{\text {hitung }}$ sebesar 7,357 dan nilai $t_{\text {tabel }}$ sebesar 1,661 (didapat dari $t_{\text {tabel }}$ ) sehingga dilakukan perbandingan nilai sig. $(0,000)<$ alpha $(0,05)$ dan nilai $t_{\text {hitung }}(7,357)>t_{\text {tabel }}(1,661)$ maka terdapat pengaruh positif dan signifikan antara variabel atribut produk dan perpindahan merek.

\section{Uji T Variety Seeking $\left(\mathrm{X}_{2}\right)$ Terhadap Perpindahan Merek (Y)}

Tabel 4.12

Uji T $\mathrm{X}_{2}$ dan $\mathrm{Y}$

\begin{tabular}{|l|l|r|c|}
\hline \multirow{2}{*}{ Model } & \multicolumn{1}{|c|}{ t } & Sig. \\
\hline \multirow{2}{*}{1} & (Constant) & 13.448 & .000 \\
\cline { 2 - 4 } & Atribut Produk & $\mathbf{7 . 9 7 4}$ & $\mathbf{. 0 0 0}$ \\
\hline \multicolumn{3}{|l|}{ a. Dependent Variable: Perpindahan Merek } \\
\hline
\end{tabular}

Berdasarkan tabel 4.33 didapat nilai sig. sebesar 0,000 , nilai thitung sebesar 7,974 dan nilai $t_{\text {tabel }}$ sebesar 1,661 (didapat dari $t_{\text {tabel }}$ ) sehingga dilakukan perbandingan nilai sig. $(0,000)<$ alpha $(0,05)$ dan nilai thitung $(7,974)>t_{\text {tabel }}(1,661)$ maka terdapat pengaruh positif dan signifikan antara variabel variety seeking dan perpindahan merek

\section{Uji T Promosi $\left(\mathrm{X}_{3}\right)$ Terhadap Perpindahan Merek (Y)}

Tabel 4.13

Uji T $\mathrm{X}_{4}$ dan $\mathrm{Y}$

\begin{tabular}{|l|l|r|c|}
\hline \multirow{2}{*}{ Model } & $\mathbf{t}$ & Sig. \\
\hline \multirow{2}{*}{1} & (Constant) & 13.114 & .000 \\
\cline { 2 - 4 } & Atribut Produk & $\mathbf{7 . 5 0 0}$ & $\mathbf{. 0 0 0}$ \\
\hline \multicolumn{3}{|l|}{ a. Dependent Variable: Perpindahan Merek } \\
\hline
\end{tabular}


Berdasarkan tabel 4.34 didapat nilai sig. sebesar 0,000, nilai $t_{\text {hitung }}$ sebesar 7,500 dan nilai $t_{\text {tabel }}$ sebesar 1,661 (didapat dari $t_{\text {tabel }}$ ) sehingga dilakukan perbandingan nilai sig. $(0,000)<$ alpha $(0,05)$ dan nilai $t_{\text {hitung }}(7,500)>t_{\text {tabel }}(1,661)$ maka terdapat pengaruh positif dan signifikan antara variabel promosi dan perpindahan merek.

\section{Uji T Harga $\left(\mathrm{X}_{4}\right)$ Terhadap Perpindahan Merek (Y)}

Tabel 4.14

\begin{tabular}{|c|c|c|c|}
\hline \multicolumn{4}{|c|}{ Uji T $X_{5}$ dan $Y$} \\
\hline \multicolumn{2}{|c|}{ Model } & $\mathbf{t}$ & Sig. \\
\hline \multirow[t]{2}{*}{1} & (Constant) & 12.623 & .000 \\
\hline & Atribut Produk & 8.039 & .000 \\
\hline
\end{tabular}

Berdasarkan tabel 4.35 didapat nilai sig. sebesar 0,000, nilai $t_{\text {hitung }}$ sebesar 8,039 dan nilai $t_{\text {tabel }}$ sebesar 1,661 (didapat dari $t_{\text {tabel }}$ ) sehingga dilakukan perbandingan nilai sig. $(0,000)<$ alpha $(0,05)$ dan nilai $t_{\text {hitung }}(8,039)>t_{\text {tabel }}(1,661)$ maka terdapat pengaruh positif dan signifikan antara variabel harga dan perpindahan merek.

\section{PEMBAHASAN}

\section{Pengaruh Atribut Produk ( $\left.X_{1}\right)$ Terhadap Perpindahan Merek (Y)}

Berdasarkan tabel 4.30 dapat dilihat bahwa variabel atribut produk mendapatkan hasil

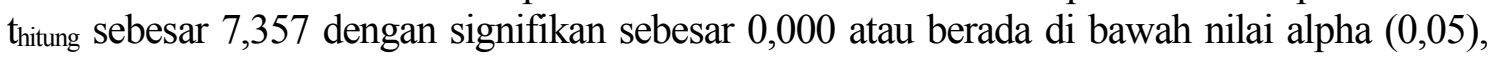
sehingga dalam hasil pengujian ini mendukung $\mathrm{H} 1$ secara empirik yang berarti atribut produk berpengaruh positif terhadap perpindahan merek. Dan berdasarkan persepsi responden dari atribut produk Tri bahwa sinyal dari operator Tri lebih lambat dan kurang baik jika dibanding dengan operator lain dengan demikian hubungan keduanya antara variabel atribut produk terhadap perpindahan merek memiliki pengaruh dalam penelitian ini.

Penelitian ini relevan dengan hasil penelitian sebelumnya yang dilakukan oleh (Ananda, 2012) dengan judul "Pengaruh Atribut Produk, Harga dan Promosi Terhadap Perilaku Brand Switching ke Telkomsel Sosialita" dengan hasil mengatakan bahwa atribut produk berpengaruh positif terhadap perilaku brand switching.

Hal ini terbukti dengan adanya keselarasan antara hasil penelitian sebelumnya dengan penelitian ini bahwa atribut produk berpengaruh positif terhadap perpindahan merek. Sesuai dengan teori Fatihudin \& Firmansyah (2019:94) yang menyatakan bahwa terdapat suatu resiko dimana konsumen yang loyal akan bisa dipengaruhi pesaing jika penampilan produk atau layanannya tidak diperbaiki.

\section{Pengaruh Variety Seeking $\left(\mathrm{X}_{2}\right)$ Terhadap Perpindahan Merek (Y)}

Berdasarkan tabel 4.31 dapat dilihat bahwa variabel variety seeking mendapatkan hasil $t_{\text {hitung }}$ sebesar 7,974 dengan signifikan sebesar 0,000 atau berada di bawah nilai alpha $(0,05)$, sehingga dalam hasil pengujian ini mendukung $\mathrm{H} 2$ secara empirik yang berarti variety seeking berpengaruh positif terhadap perpindahan merek. Dan berdasarkan persepsi responden dari variety seeking bahwa paket internet Tri masih belum beragam jika dibandingkan dengan paket internet lain dengan demikian hubungan keduanya antara variabel variety seeking terhadap perpindahan merek memiliki pengaruh dalam penelitian ini. 
Penelitian ini relevan dengan hasil penelitian sebelumnya yang dilakukan oleh (Nuraeni, 2014) dengan judul "Analisis Faktor-Faktor yang Mempengaruhi Perilaku Brand Switching pada Kartu Prabayar XL" dengan hasil mengatakan bahwa variabel variety seeking berpengaruh positif terhadap perilaku brand switching.

Hal ini terbukti dengan adanya keselarasan antara hasil penelitian sebelumnya dengan penelitian ini bahwa variety seeking berpengaruh positif terhadap perpindahan merek. Sesuai dengan teori Peter \& Olson (2014:77) yang menyatakan bahwa konsumen selalu mengalami kejenuhan dan hasrat untuk memenuhi kebutuhannya sering berubah-ubah sehingga konsumen selalu mnecari varians yang lebih unggul dan mudah didapat.

\section{Pengaruh Promosi $\left(\mathbf{X}_{3}\right)$ Terhadap Perpindahan Merek (Y)}

Berdasarkan tabel 4.32 dapat dilihat bahwa variabel promosi mendapatkan hasil $t_{\text {hitung }}$ sebesar 7,500 dengan signifikan sebesar 0,000 atau berada di bawah nilai alpha $(0,05)$, sehingga dalam hasil pengujian ini mendukung H3 secara empirik yang berarti promosi berpengaruh positif terhadap perpindahan merek. Dan berdasarkan persepsi responden dari promosi Tri bahwa perusahaan Tri masih kurang menarik dalam menyampaikan informasi terkait produknya dengan demikian hubungan keduanya antara variabel promosi terhadap perpindahan merek memiliki pengaruh dalam penelitian ini.

Penelitian ini relevan dengan hasil penelitian sebelumnya yang dilakukan oleh (Rizal \& Purwanto, 2018) dengan judul "Pengaruh Penerapan Kebijakan 7P Terhadap Perilaku Brand Switching pada Pengguna Kartu GSM Prabayar XL Axiata di Kota Pontianak" dengan hasil mengatakan bahwa variabel promosi berpengaruh positif terhadap perilaku brand switching.

Hal ini terbukti dengan adanya keselarasan antara hasil penelitian sebelumnya dengan penelitian ini bahwa promosi berpengaruh positif terhadap perpindahan merek. Sesuai dengan teori Suryati (2015:60) yang menyatakan bahwa mengkomunikasikan produnya kepada konsumen merupakan salah satu bentuk untuk mendorong konsumen agar bertindak dalam hal membeli.

\section{Pengaruh Harga $\left(\mathrm{X}_{4}\right)$ Terhadap Perpindahan Merek (Y)}

Berdasarkan tabel 4.33 dapat dilihat bahwa variabel harga mendapatkan hasil thitung sebesar 8,039 dengan signifikan sebesar 0,000 atau berada di bawah nilai alpha $(0,05)$, sehingga dalam hasil pengujian ini mendukung $\mathrm{H} 4$ secara empirik yang berarti harga berpengaruh positif terhadap perpindahan merek. Dan berdasarkan persepsi responden dari harga bahwa perusahaan Tri memberikan harga yang terjangkau namun hasil atau manfaat yang didapat konsumen tidak sesuai harapan memenuhi kebutuhannya dengan demikian hubungan keduanya antara variabel harga terhadap perpindahan merek memiliki pengaruh dalam penelitian ini.

Penelitian ini relevan dengan hasil penelitian sebelumnya yang dilakukan oleh (Adzim, 2018) dengan judul "Pengaruh Produk, Harga, Promosi, Saluran Distribusi dan Proses Terhadap Keputusan Brand Switching pada Kartu Telepon Seluler" dengan hasil mengatakan bahwa variabel harga berpengaruh positif terhadap keputusan brand switching.

Hal ini terbukti dengan adanya keselarasan antara hasil penelitian sebelumnya dengan penelitian ini bahwa harga berpengaruh positif terhadap perpindahan merek. Sesuai dengan teori Indrasari (2019:36) yang menyatakan bahwa harga dapat mempengaruhi posisi persaingan perusahaan dengan suatu keputusan jika melakukan penurunan harga dapat menaikan penjualan, sedangkan pada produk yang membawa 
citra bergengsi kenaikan harga akan menaikan penjualan sebab produk dengan harga tinggi akan menunjukan prestige seseorang.

\section{PENUTUP}

\section{SIMPULAN}

1. Terdapat pengaruh positif dan signifikan atribut produk $\left(X_{1}\right)$ terhadap perpindahan merek (Y) pengguna jaringan operator Tri ke operator lain di masa pembelajaran online saat pandemi covid-19.

2. Terdapat pengaruh positif dan signifikan variety seeking $\left(\mathrm{X}_{2}\right)$ terhadap perpindahan merek $(\mathrm{Y})$ pengguna jaringan operator Tri ke operator lain.

3. Terdapat pengaruh positif dan signifikan promosi $\left(\mathrm{X}_{3}\right)$ terhadap perpindahan merek (Y) pengguna jaringan operator Tri ke operator lain.

4. Terdapat pengaruh positif dan signifikan harga $\left(\mathrm{X}_{4}\right)$ terhadap perpindahan merek (Y) pengguna jaringan operator Tri ke operator lain.

\section{SARAN}

\section{Bagi Perusahaan}

1. Berdasarkan persepsi responden dari variabel atribut produk pada operator Tri terdapat item pernyataan dengan hasil terendah dan pernyataan tersebut ialah sinyal dari operator Tri lebih lambat dan kurang baik jika dibanding dengan operator lain, maka sebaiknya jangkauan sinyal Tri agar dapat diperbaiki untuk dapat terjangkau dimanapun pengguna Tri berada dengan perlu memasang alat penguat sinyal di berbagai lokasi atau titik.

2. Berdasarkan persepsi responden dari variabel variety seeking pada operator Tri terdapat item pernyataan dengan hasil terendah dan pernyataan tersebut ialah paket internet Tri baik kuota maupun unlimited kurang beragam jika dibandingkan dengan paket internet dari operator lain. Maka sebaiknya operator Tri lebih dikembangkan lagi paket internetnya agar dapat menyamai atau bahkan lebih unggul dari operator lain.

3. Berdasarkan persepsi responden dari variabel promosi pada operator Tri terdapat item pernyataan dengan hasil terendah dan pernyataan tersebut ialah iklan dari operator Tri kurang menarik perhatian konsumen. Maka sebaiknya perusahaan Tri perlu melakukan inovasi dan kreativitas pada iklan sehingga menjadi daya tarik konsumen untuk menggunakannya.

4. Berdasarkan persepsi responden dari variabel harga pada operator Tri terdapat item pernyataan dengan hasil terendah dan pernyataan tersebut ialah harga yang ditawarkan operator Tri belum memberikan manfaat yang diinginkan pengguna. Maka sebaiknya perusahaan Tri memberikan harga yang relatif agak murah serta harga yang sesuai dengan hasil kualitas jaringan.

5. Berdasarkan persepsi responden dari variabel perpindahan merek pengguna operator Tri terdapat item pernyataan dengan hasil terendah dan pernyataan tersebut ialah pengguna Tri sering melakukan percobaan pada produk operator lain dikarenakan ingin melepas kejenuhan dari produk operator Tri. Maka bisa dihindari apabila Tri bisa meningkatkan dari segi kualitas salah satunya jaringan agar pengguna Tri tidak melakukan percobaan pada operator lain. 


\section{Bagi Penelitian Selanjutnya}

1. Untuk meneliti faktor-faktor lainnya yang tidak diteliti dalam penelitian ini diantaranya gaya hidup, citra merek, iklan dan ketidakpuasan.

2. Untuk melakukan peninjauan dan observasi yang cakupannya lebih luas tidak hanya di lokasi UIA saja dan objek produknya masih banyak dari jaringan seluler lainnya atau dari jenis produk lainnya.

\section{DAFTAR PUSTAKA}

Al-Qur'an dan Terjemahan

Aditama, R. A. 2020. Pengantar Manajemen: Teori dan Aplikasi. AE Publishing. Malang. Adzim, F. 2018. Pengaruh Produk, Harga, Promosi, Saluran Distribusi dan Proses Terhadap Keputusan Brand Switcing pada Kartu Telepon Seluler. Manajemen Bisnis. 4(2): 39-48.

Ananda, H. R. 2012. Pengaruh Atribut Produk, Harga dan Promosi Terhadap Perilaku Brand Switching ke Telkomsel Sosialita. Jurnal Ilmiah Mahasiswa. 1(2).

Azhary, A. 2013. Pengaruh Atribut Produk dan Variety Seeking Terhadap Perilaku Beralih Merek (Brand Switching) Kartu Telepon Seluler. Skripsi. Universitas Negeri Malang.

Dharmmesta, B. S., \& Handoko, T. H. 2012. Manajemen Pemasaran : Analisa Perilaku Konsumen. BPFB.Yogyakarta.

Fatihudin, D., \& Firmansyah, A. 2019. Pemasaran Jasa (Strategi, Mengukur Kepuasan dan Loyalitas Pelanggan). Deepublish Publisher. Yogyakarta.

Firmansyah, A. 2018. Perilaku Konsumen (Sikap dan Pemasaran). Deepublish Publisher. Yogyakarta.

Foster, B., \& Sidharta, I. 2019. Dasar-Dasar Manajemen. Cetakan 2. Diandra Kreatif. Yogyakarta. Gunawan, C. 2018. Mahir Menguasi SPSS (Mudah Mengolah Data Dengan IBM SPSS STATISTIC 25). Deepublish Publisher. Yogyakarta.

Hanantyo, R. 2015. Pengaruh Atribut Produk, Persepsi Harga dan Keinginan Mencari Variasi Terhadap Perilaku Perpindahan Merk Produk Operator Indosat dan Telkomsel. Skripsi. Fakultas Ekonomi Universitas Negeri Jakarta.

Hawkins, D., \& Mothersbaugh, D. 2016. Consumer Behavior. 13th Edition. McGraw-Hill. Herlina, V. 2019. Panduan Praktis Mengolah Data Kuesioner Menggunakan SPSS. PT Elex Media Komputindo. Jakarta.

Indrasari, M. 2019. Pemasaran dan Kepuasan Pelanggan. Unitomo Press. Surabaya. Mowen, J. ., \& Minor, M. 2012. Perilaku Konsumen. Jilid 1 (Kelima). Erlangga. Jakarta. Musfar, T. F. 2020. Manajemen Pemasaran. Media Sains Indonesia. Bandung.

Nuraeni. 2014. Analisis Faktor-Faktor yang Mempengaruhi Perilaku Brand Switching pada Kartu Prabayar XL (Studi pada Konsumen Pandumedia Reload Service Singosari Malang). Jurnal Sketsa Bisnis. 1(1): 1-15.

Nurdiansyah, H., \& Rahman, R. S. 2019. Pengantar Manajemen. Diandra Kreatif. Yogyakarta. Peter, J. P., \& Olson, J. C. 2014. Perilaku Konsumen dan Strategi Pemasaran. Jilid 2. Salemba Empat. Jakarta. 
Putranto, A. T. 2018. Pengaruh Atribut Produk, Promosi dan Variety Seeking Terhadap Brand Switching Kartu Perdana Indosat. Jurnal Ilmiah Semarak. 1(3): 20-38.

Rizal, M. F., \& Purwanto, E. 2018. Pengaruh Penerapan Kebijakan 7P Terhadap Perilaku Brand Switching pada Pengguna Kartu GSM Prabayar XL Axiata. eJurnal Equilibrium Manajemen. 4(1): 43-52.

Schiffman, L. G., \& Kanuk. 2015. Consumer Behavior. (11 ed.). Pearson Education. Boston. Shinta, A. 2011. Manajemen Pemasaran. UB Press. Malang.

Sumarwan, U. 2014. Perilaku Konsumen Teori dan Penerapannya dalam Pemasaran. Liberty. Yogyakarta.

Suprapto, R., \& Azizi, Z. W. 2020. Manajemen Pemasaran. Myria Publisher. Ponorogo. Suryati, L. 2015. Manajemen Pemasaran. Deepublish Publisher. Yogyakarta.

Tersiana, A. 2020. Metode Penelitian. Anak Hebat Indonesia. Yogyakarta. 